\title{
Efficient adsorption of dibutyl phthalate from aqueous solution by activated carbon developed from phoenix leaves
}

\author{
Z. Wang
}

Received: 28 August 2013/Revised: 13 December 2013/Accepted: 12 March 2014/Published online: 9 April 2014

(C) Islamic Azad University (IAU) 2014

\begin{abstract}
The adsorption of dibutyl phthalate (DBP) from aqueous solution using phoenix leaves activated carbon (PLAC) by chemical activation with phosphate was investigated. After scanning electron microscopy, energy dispersive X-ray spectrometry, Brunauer-Emmett-Teller (BET) and infrared spectrum characterization of PLAC, the influences of solution $\mathrm{pH}$, contact time, initial DBP concentration and temperature on the adsorption rate were investigated. The isotherm, kinetic and thermodynamic parameters were explored to describe the experimental data. The PLAC has a heterogeneous distribution of grain and a well-developed porous structure. The main elements of PLAC are $24.26 \%$ carbon, $70.65 \%$ oxygen and $3.75 \%$ phosphor. The BET surface area of the sample is $593.52 \mathrm{~m}^{2} / \mathrm{g}$ with the average pore diameter of $6.31 \mathrm{~nm}$. The single-point total pore volume was found to be $0.52 \mathrm{~cm}^{3} / \mathrm{g}$. The infrared spectrum showed the complexity of the material. The maximum DBP adsorption rate was $97.36 \%$, and the maximum adsorption capacity was $48.68 \mathrm{mg} / \mathrm{g}$ at $\mathrm{pH} 13$. The monolayer sorption capacity of the biosorbent for DBP was found as $133.33 \mathrm{mg} / \mathrm{g}$ with the Langmuir isotherm. The equilibrium data fitted with Freundlich isotherm better than Langmuir, Dubinin-Radushkevich and Temkin isotherm. The kinetic data were best described by the pseudo-second-order model better than pseudo-first-order kinetic, intraparticle diffusion, and Elovich model. The thermodynamic studies indicated that the sorption process spontaneous, thermodynamically
\end{abstract}

Z. Wang $(\bowtie)$

School of Civil Engineering, Nanjing Forestry University, Longpan Road 159\#, Nanjing 210037, People's Republic of China

e-mail: wangzheng@njfu.edu.cn favorable and endothermic. The PLAC can be an alternative material for treatment of DBP wastewater.

Keywords Adsorption - Dibutyl phthalate $\cdot$ Phoenix leaves activated carbon - Isotherm - Kinetic model · Thermodynamic study

\section{Introduction}

Phthalate esters (PAEs) are synthetic compounds mainly used as plasticizers to improve the mechanical properties of plastic resin, particularly enhancing flexibility (Fang et al. 2010). PAEs are not acutely toxic but exposure over a reasonable period could probably result in potential carcinogenic effects and an unfavorable influence on the hormonal and reproduction system (via estrogenic effects) (Julinova and Slavik 2012). Among PAEs, dibutyl phthalate (DBP) is one of the most widely used, with consumption growing rapidly both globally and locally in China. The Health Ministry of People's Republic of China, under the Standards for drinking water quality of China (GB5749-2006), regulates the maximum DBP contaminant level of whole country's drinking water be $3 \mu \mathrm{g} / \mathrm{L}$ (Health Ministry of People's Republic of China 2007).

Literatures describe a number of methods for removing DBP from the environment such as microbial degradation (Chang et al. 2009; Chi and Yang 2012; Fang et al. 2009), photo degradation (Ooka et al. 2004; Li et al. 2005), ozonation ( $\mathrm{Li}$ et al. 2006) and adsorption (Salim et al. 2010; Mendez-Diaz et al. 2012; Fang and Huang 2009). Adsorption is a term commonly used for several different processes involving physical as well as chemical interactions between the solid surface of a substance and a dissolved material. Adsorption is an economical and effective 
process (Dubey and Shiwani 2012). The most applicable removal method of DBP is adsorption using activated carbon and the maximum adsorption capacity of DBP up to $104.7 \mathrm{mg} / \mathrm{g}$ with nutshell activated carbon in research of Fang and Huang. But, the adsorption using activated carbon has been shown to be nonselective and expensive, its performance depending on the type of carbon used; the higher the quality the greater the cost (Crini 2005). In order to reduce the price of activated carbon, in recent years, industrial and agricultural by-products are increasingly being investigated as precursors (Carvalho et al. 2003). The waste leaves of Casurina equisetifolia has been used as a low-cost raw material for the preparation of activated carbons and the carbons have been used for adsorption of chromium from aqueous solution successfully (Ranganathan 2000).

Phoenix tree has a large number of planting area in China as a landscape tree species. Fallen leaves of phoenix are in great supply, inexpensive, easily available and no commercial usage. However, there have been no previous published literatures on the use of activated carbon manufactured with phoenix leaves for removing DBP from aqueous solution. So, the phoenix leaves as a low-cost and abundant biomass resource could be a choice to prepare activated carbon for the removal of DBP from wastewater or drinking water and the cost of DBP treatment could be greatly reduced.

In the present study, the phoenix leaves activated carbon (PLAC) was prepared through phosphate chemical activation method and the removal characteristics of DBP from aqueous solution with this kind of low-cost bioadsorbent was performed. After scanning electron microscopy (SEM), EDS, BET and FTIR characterization of this activated carbon, the influences of different parameters including solution $\mathrm{pH}$, DBP concentration, contact time and temperature were investigated. The adsorption isotherm, kinetic and thermodynamic parameters were also explored to describe the experimental data. This research was conducted in Watertreatment Laboratory, Nanjing Forestey University, People's Republic of China during January to August 2012.

\section{Materials and methods}

Activated carbon sample preparation and characterization

Samples of phoenix leaves (Fig. 1a) were obtained from the campus of Nanjing Forestry University in December, 2011. The samples were washed using distilled water and dried in a muffle heater at $323 \mathrm{~K}$ for $24 \mathrm{~h}$. Then, the dried samples were pulverized to pass 50 -mesh sieves with diameter $355 \mu \mathrm{m}$ (Fig. 1b). Weighed samples were carbonized in the muffle furnace under nitrogen atmosphere. The chemical-impregnated samples were subjected to twostage activation. First, $20 \mathrm{~g}$ of phoenix leaves powder sample was immersed in $100 \mathrm{~mL}$ of aqueous solution of phosphate (30\% volume concentration) at room temperature for $5 \mathrm{~h}$. Second, the temperature was increased to $343 \mathrm{~K}$ at a heating rate of $5 \mathrm{~K} / \mathrm{min}$. The sample was exposed to this temperature for $5 \mathrm{~h}$. It was then cooled to ambient temperature and left at rest for $10 \mathrm{~h}$. After the treatment, the samples were filtered (Fig. 1c) and dried at $373 \mathrm{~K}$ for $24 \mathrm{~h}$ to ensure complete removal of water. For the carbonization, the samples were heated at $5 \mathrm{~K} / \mathrm{min}$ to $373 \mathrm{~K}$ and held for $1 \mathrm{~h}$. Then, the temperature was increased in steps of $15 \mathrm{~K} / \mathrm{min}$ to the desired temperature $823 \mathrm{~K}$, which was held constant for $2 \mathrm{~h}$. Then, the sample was cooled to ambient temperature. The carbonization was done under flow of nitrogen $(200 \mathrm{~mL} / \mathrm{min})$. Finally, the PLAC (Fig. 1d) obtained was crushed with grind, thoroughly washed with distilled water until neutral, and then dried in a vacuum oven at $333 \mathrm{~K}$ for $10 \mathrm{~h}$ (Jibril et al. 2008).

The Brunauer-Emmett-Teller (BET) surface area and total pore volume of the activated carbon sample were determined using a surface analyzer (Quantachrome Instrument, USA). Nitrogen was used as cold bath (77.35 K). FTIR spectrometer (Model 360, Thermo Nicolet Instrument, USA) was employed to determine the presence of functional groups in all the adsorbents at room temperature. Pellet (pressed-disk) technique was used for this purpose. The pellets were prepared by mixing the adsorbent with $\mathrm{KBr}$ (mass ratio 100:1). The spectral range covered was from 4,000 to $500 \mathrm{~cm}^{-1}$ scanned at the rate of $16 \mathrm{~nm} / \mathrm{s}$. A scanning electron microscope (Quanta 200, FEI Instrument, Holand) was used for obtaining SEM micrographs of the PLAC. Samples of activated carbon were all gold plated and an electron acceleration voltage of $20 \mathrm{kV}$ was applied for SEM observation. The predominant elements of PLAC were analyzed using Energy dispersive $\mathrm{X}$-ray spectrometry (EDS) (INCA, Oxford Instruments, England).

Adsorbate and analytical measurements

A stock DBP solution of $1,000 \mathrm{mg} / \mathrm{L}$ was prepared from DBP (99 \% purity, $\mathrm{C}_{16} \mathrm{H}_{22} \mathrm{O}_{4}$, FW: 278.34, AccuStandard Inc, USA) dissolved with methanol. The working solutions with different concentrations were prepared by appropriate dilutions of the stock solution. The concentration of DBP in aqueous solution was analyzed by a high-performance liquid chromatograph (HPLC, Model LaChrom Elite L-2000, Hitachi Instrument, Japan) using an HITACHI LaChrom C $18(5 \mu \mathrm{m}) 4.6 \mathrm{~mm}$ I.D. $\times 150 \mathrm{~mm}$ separation 
Fig. 1 The steps for preparing the phoenix leaves activated carbon (PLAC): a raw material (phoenix leaves), b after pulverizing (phoenix leaves powder), $\mathbf{c}$ after activating and filtering, $\mathbf{d}$ activated carbon cooled to ambient temperature
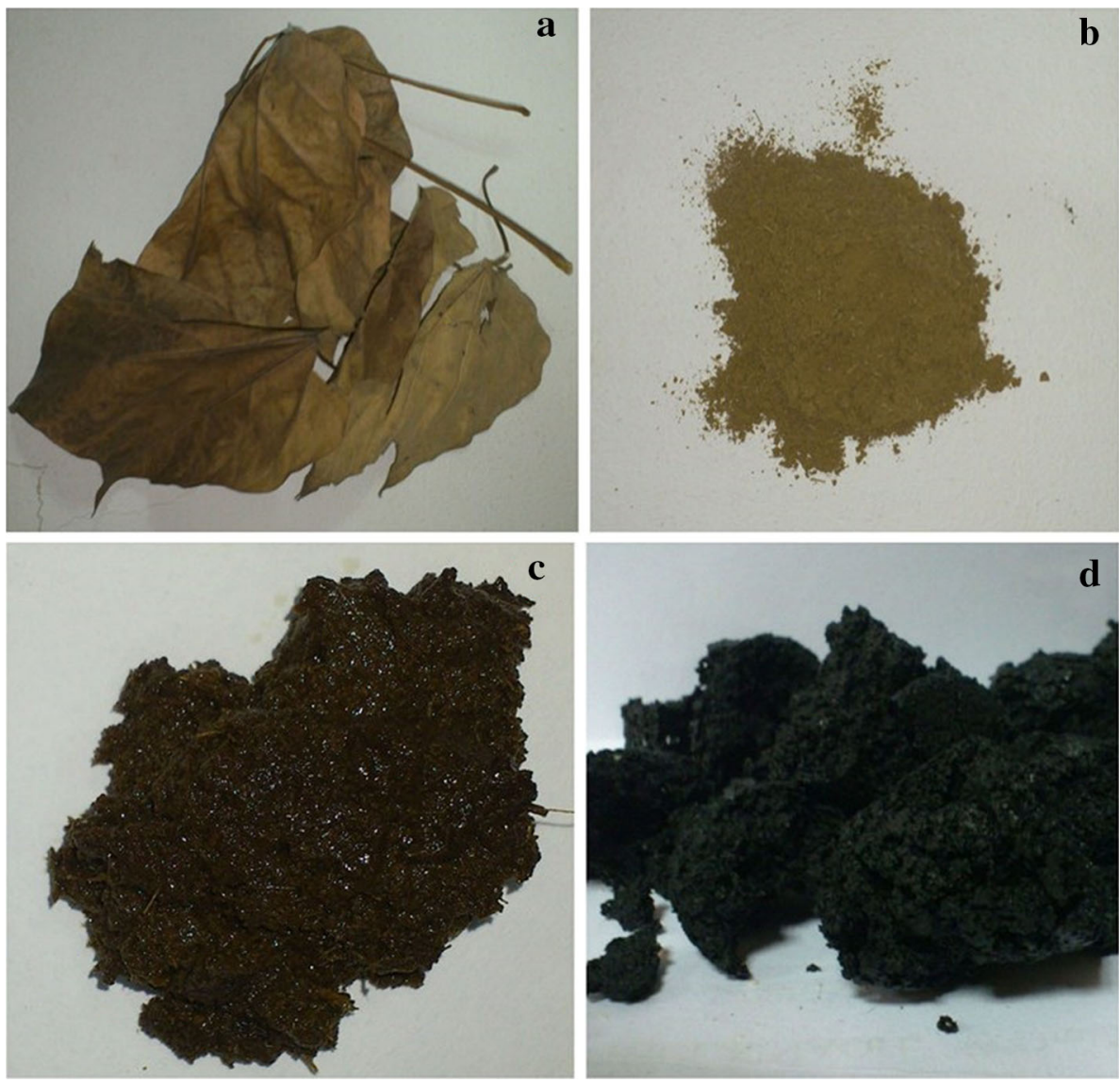

column at $202 \mathrm{~nm}$ wavelength. The mobile phase was a mixture of water and methanol (10:90, v/v), and the flow rate was $1.0 \mathrm{~mL} / \mathrm{min}$. The injection volume was $10 \mu \mathrm{L}$, and the column temperature was $303 \mathrm{~K}$. Under this chromatographic condition, baseline separation for DBP could be obtained within $15 \mathrm{~min}$ (Ren et al. 2012). A digital $\mathrm{pH}$ meter of PSI CO. LTD, Shanghai, China (PHS-3C), was used for $\mathrm{pH}$ measurement.

\section{Batch adsorption experiments}

A typical adsorption experiment was conducted by using the necessary PLAC in a 250-mL stopper conical flask batch at desired $\mathrm{pH}$ value, contact time, temperature and DBP concentration. The $\mathrm{pH}$ values of the solution were adjusted by adding negligible volumes of $0.1 \mathrm{M} \mathrm{HCl}$ or $\mathrm{NaOH}$. The flask was shaken for the desired contact time in a rotary shaker fixed at $120 \mathrm{rpm}$. The contents of the flask were filtered through $0.45-\mu \mathrm{m}$ filter membrane and the filtrate was analyzed for remaining DBP concentration in the samples. The removal percentage of DBP was determined from the initial and final concentrations of DBP in the liquid phases. The $\mathrm{pH}$ of the solutions was checked before beginning and at the end of the adsorption experiments.
The percentage of DBP adsorption by the PLAC was computed using the equation:

Adsorption percentage, $\%=\frac{C_{0}-C_{t}}{C_{0}} \times 100$

where $C_{0}$ and $C_{\mathrm{t}}$ are the concentrations of DBP $(\mathrm{mg} / \mathrm{L})$ in the solution initial and at time $t$ (min). Adsorption capacity was calculated by using the mass balance equation for the adsorbent:

$q=\frac{\left(C_{0}-C_{\mathrm{e}}\right) V}{M}$

where $q$ is the adsorption capacity $(\mathrm{mg} / \mathrm{g}), C_{\mathrm{e}}$ is the equilibrium concentrations of DBP $(\mathrm{mg} / \mathrm{L})$ in the solution. $V$ is the volume of DBP solution (L) and $M$ is the weight of $\operatorname{PLAC}(\mathrm{g})$.

The effect of $\mathrm{pH}$ on DBP removal was investigated in the initial $\mathrm{pH}$ range of $1-13$. Adsorption experiments for the effect of $\mathrm{pH}$ were conducted by using $100 \mathrm{~mL}$ DBP solution having $5 \mathrm{mg} / \mathrm{L}$ concentration with PLAC dosage of $0.1 \mathrm{~g} / \mathrm{L}$ for a contact time of $2 \mathrm{~h}$ at $298 \mathrm{~K}$. The effect of PLAC dosage level on percent removal of DBP was studied using $100 \mathrm{~mL}$ DBP solution having $5 \mathrm{mg} / \mathrm{L}$ concentration. The selected PLAC was used at dosage ranging from 0.1 to $1 \mathrm{~g} / \mathrm{L}$ for a contact time of $2 \mathrm{~h}$ at $298 \mathrm{~K}$. Effect 
Fig. 2 SEM photographs of phoenix leaves activated carbon $(\mathrm{PLAC})$ at $\times 500(\mathbf{a}), 1,000(\mathbf{b})$, 2,000 (c) and 4,000

(d) magnification
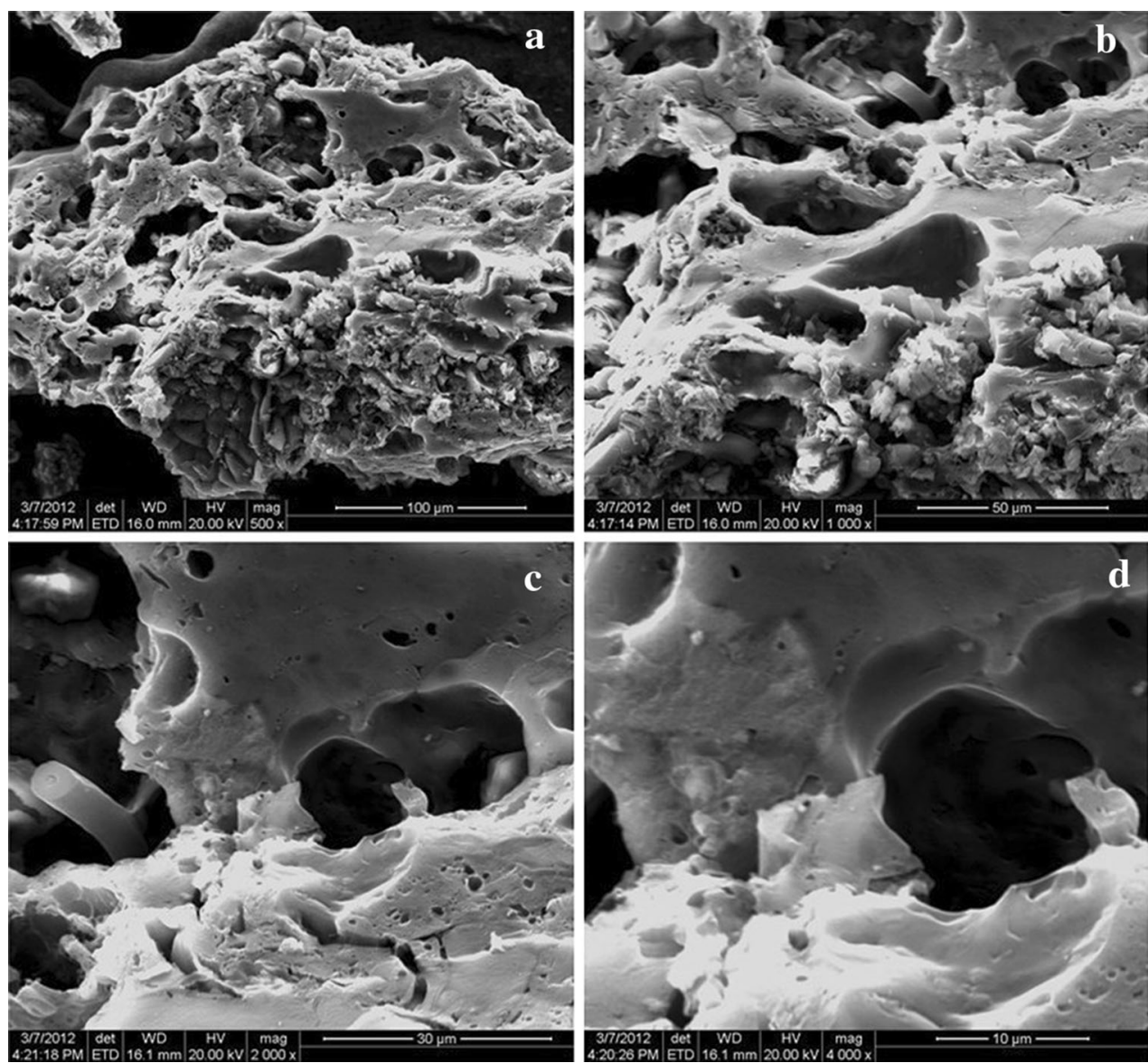

on variation of solution initial concentration was studied using $100 \mathrm{~mL}$ DBP solution of concentration $5-15 \mathrm{mg} / \mathrm{L}$, contact time of $2 \mathrm{~h}$ and PLAC dosage level of $0.1 \mathrm{~g} / \mathrm{L}$ at $298 \mathrm{~K}$. Kinetics analysis for the adsorption process was studied on the batch adsorption of $100 \mathrm{~mL}$ DBP solution having $5 \mathrm{mg} / \mathrm{L}$ concentration with PLAC dosage of 0.1 $\mathrm{g} / \mathrm{L}$. The contact time was varied from 20 to $120 \mathrm{~min}$ at $298 \mathrm{~K}$. The effect of temperature was evaluated using $100 \mathrm{~mL}$ DBP solution having $5 \mathrm{mg} / \mathrm{L}$ concentration with PLAC dosage of $0.1 \mathrm{~g} / \mathrm{L}$ for a contact time of $2 \mathrm{~h}$. The selected temperatures were ranging from 298 to $308 \mathrm{~K}$. The adsorption experiment on each sample was conducted three times, and each individual chemical assay was conducted in duplicate.

\section{Results and discussion}

Characterization of the PLAC

The SEM micrographs of PLAC were shown in Fig. 2 at $500,1,000,2,000$ and 5,000 times magnification. From Fig. 2, we can see that a heterogeneous distribution of grain and a well-developed porous structure with different

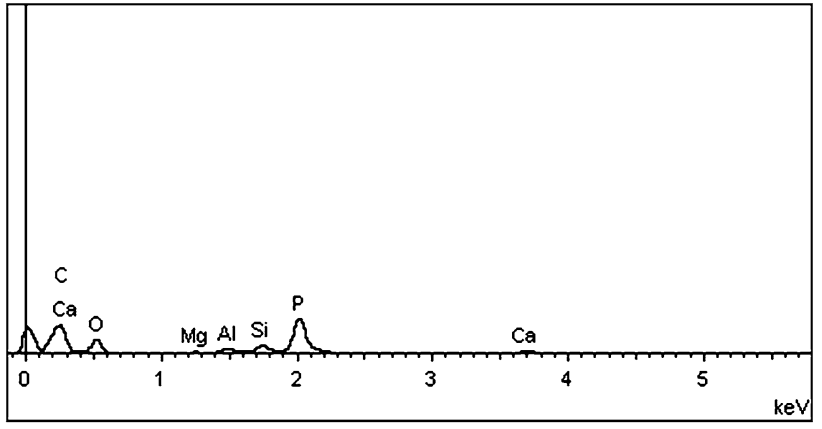

Fig. 3 EDS of phoenix leaves activated carbon (PLAC)

small-size pore. At the same position of tested sample (Fig. 2a, b, c), we can even find a short leaf vein after carbonization with clear shape. Figure $2 \mathrm{~d}$ showed an existence of cavity with $10 \mu \mathrm{m}$ diameter, attributed to the evaporation of organic matter and cellulose due to the phosphate activation reaction and carbonization process.

EDS analysis of PLAC was indicated in Fig. 3. The EDS analysis conclusions were enumerated in Table 1. From the analysis conclusion of Table 1 , we can find that the main elements of PLAC being $24.26 \%$ carbon, 
Table 1 EDS analysis conclusions of phoenix leaves activated carbon (PLAC)

\begin{tabular}{lc}
\hline Element & Weight $\%$ \\
\hline $\mathrm{C}$ & 24.26 \\
$\mathrm{Mg}$ & 0.06 \\
$\mathrm{Al}$ & 0.41 \\
$\mathrm{Si}$ & 0.58 \\
$\mathrm{P}$ & 3.75 \\
$\mathrm{Ca}$ & 0.30 \\
$\mathrm{O}$ & 70.65 \\
Totals & 100.00 \\
\hline
\end{tabular}

$70.65 \%$ oxygen and $3.75 \%$ phosphor, respectively. These three elements accounted $98.66 \%$ of the total element composition of PLAC.

The specific surface area and pore structure of PLAC were analyzed based on the nitrogen adsorption at $77.35 \mathrm{~K}$. The BET surface area of the sample was $593.52 \mathrm{~m}^{2} / \mathrm{g}$. The single-point total pore volume was found to be $0.52 \mathrm{~cm}^{3} / \mathrm{g}$, with the average pore diameter of $6.31 \mathrm{~nm}$. Pore sizes are classified in accordance with the classification adopted by the International Union of Pure and Applied Chemistry (IUPAC), that is, micropores [diameter $(d)<2 \mathrm{~nm}$ ], mesopores $(2 \mathrm{~nm}<d<50 \mathrm{~nm})$ and macropores $(d>50 \mathrm{~nm})$ (Ahmad et al. 2009). The analysis of the PLAC showed the predominance of mesoporous structure.

The infrared spectrum of PLAC was presented in Fig. 4. As shown in Fig. 4, the infrared spectrum indicated a large number of adsorption peaks, which suggested the complexity of the activated carbon material. There was strong peak at $3,457 \mathrm{~cm}^{-1}$ representing the $\mathrm{OH}$ stretching of phenol group, and the peaks at $2,941 \mathrm{~cm}^{-1}$ indicated the presence of $\mathrm{CH}_{2}$ stretching. The peak at $1,642 \mathrm{~cm}^{-1}$ showed the $\mathrm{C}=\mathrm{C}$ stretching. The adsorption peak observed around $1,387 \mathrm{~cm}^{-1}$ could be attributed to the $\mathrm{N}-\mathrm{H}$ stretching. The bond near $1,136 \mathrm{~cm}^{-1}$ indicated the existence of $\mathrm{C}=\mathrm{O}$ stretching (Kumar et al. 2008; Han et al. 2011; Lang et al. 2013). These conclusions indicated the possible involvement of those functional groups on the surface of PLAC in adsorption process.

\section{Effect of solution $\mathrm{pH}$}

The solution $\mathrm{pH}$ is a parameter of great interest in sorption processes in aqueous phase as it determines the charge of both the sorbent and the sorbate and thereby governs the sorbent-sorbate electrostatic interactions (Behera et al. 2012). Change of the adsorption capacity of DBP on PLAC with $\mathrm{pH}$ was shown in Fig. 5. From Fig. 5, the DBP adsorption capacities kept stable when solution $\mathrm{pH}$ value changed from 1 to 7 and increased when initial $\mathrm{pH}$ value changed from 9 to 13 . The maximum adsorption rate was

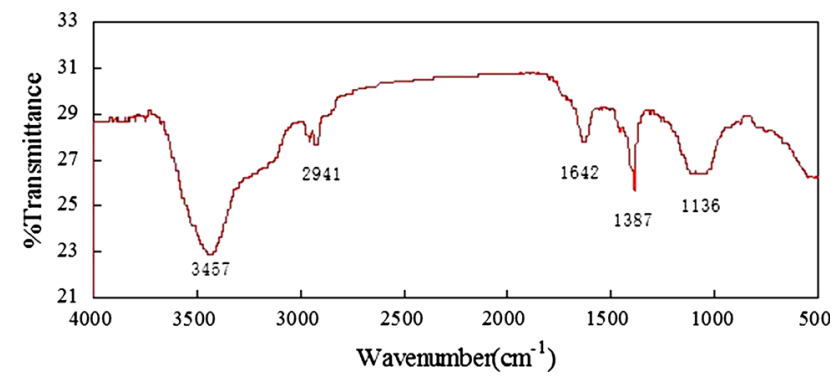

Fig. 4 FTIR spectra recorded for phoenix leaves activated carbon (PLAC)

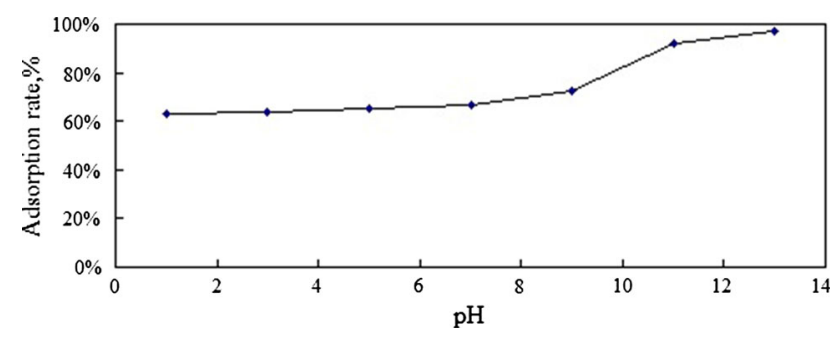

Fig. 5 Effect of pH on DBP adsorption by phoenix leaves activated carbon (PLAC)

$97.36 \%$ and the maximum adsorption capacity was $48.68 \mathrm{mg} / \mathrm{g}$ at $\mathrm{pH} 13$. The conclusion of present study on effect of solution $\mathrm{pH}$ different with conclusion reported by Fang and Huang (2009), which the optimum $\mathrm{pH}$ range for the adsorption of DBP being from 5 to 7 with nutshell activated carbon. The different surface electrochemical properties of PLAC and nutshell activated carbon may be the main reason. When the solution $\mathrm{pH}$ increased from 9 to 13 in the present test, the number of positive charged surface sites on the PLAC increased, which may result in the increase in adsorption of DBP molecules due to the electrostatic attraction (Han et al. 2011).By experiments, the $\mathrm{pH}$ of original DBP solution was not adjusted in other experiments.

\section{Adsorption isotherm}

The Langmuir-type adsorption isotherm indicates surface homogeneity of the adsorbent and hint toward the conclusion that the surface of adsorbent is made up of small adsorption patches which are energetically equivalent to each other in respect of adsorption phenomenon (Ahmad et al. 2009).The Langmuir model is given by the following Eq. (3):

$\frac{1}{q_{\mathrm{e}}}=\frac{1}{q_{\mathrm{m}} b C_{\mathrm{e}}}+\frac{1}{q_{\mathrm{m}}}$

where $q_{\mathrm{m}}$ shows the monolayer sorption capacity $(\mathrm{mg} / \mathrm{g})$, b is the Langmuir constant $(\mathrm{L} / \mathrm{mg}), C_{\mathrm{e}}$ is equilibrium dye 

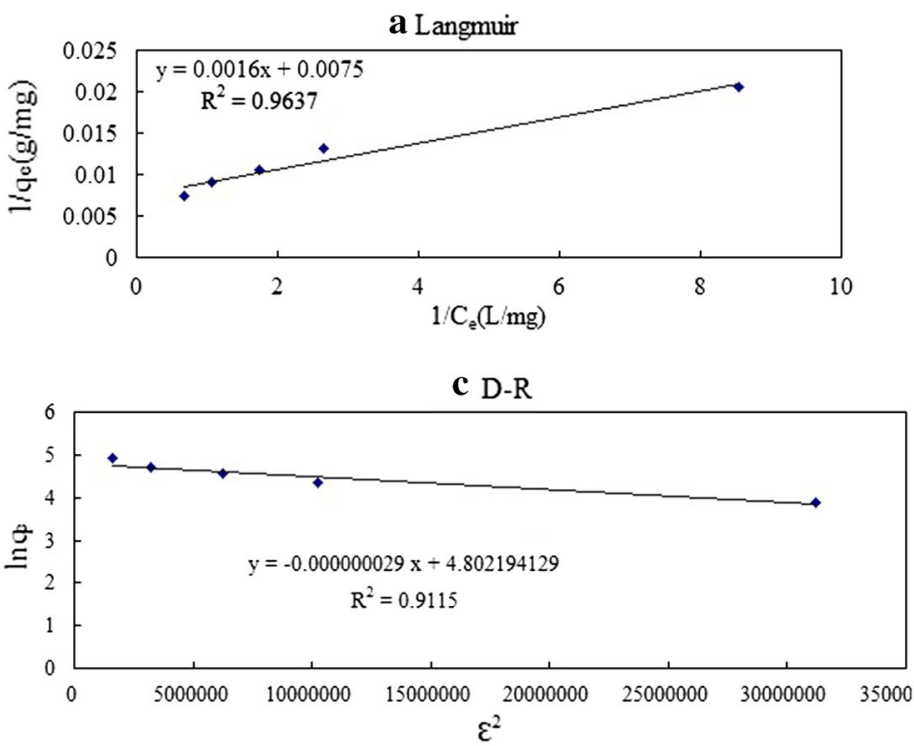

b Freundlich

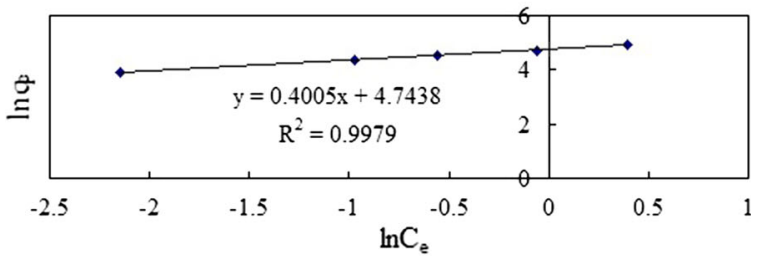

d Temkin

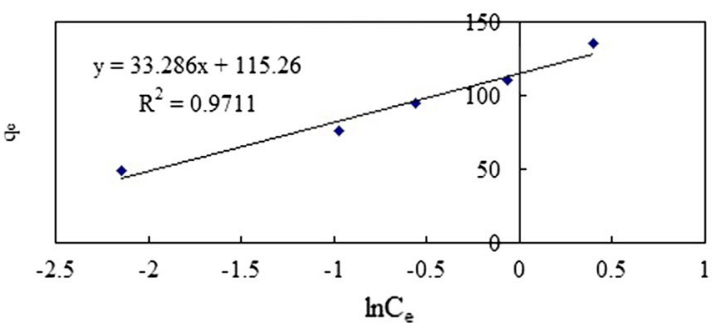

Fig. 6 The linear plots of a Langmuir, b Freundlich, c D-R equilibrium and d Temkin model

concentration in the solution $(\mathrm{mg} / \mathrm{L})$ and $q_{\mathrm{e}}$ represents amounts of DBP sorbed onto PLAC at equilibrium $(\mathrm{mg} / \mathrm{g})$. The plot of $1 / q_{\mathrm{e}}$ versus $1 / C_{\mathrm{e}}$ was employed to generate the intercept value of $1 / q_{\mathrm{m}}$ and slope of $1 / q_{\mathrm{m}} b$ (Fig. 6a).

Through calculated, $q_{\mathrm{m}}$ and $b$ were $133.33 \mathrm{mg} / \mathrm{g}$ and $4.69 \mathrm{~L} / \mathrm{mg}$, respectively. Correlation coefficient $\left(R^{2}\right)$ was 0.9637. One of the essential characteristics of the Langmuir model can be expressed in terms of the dimensionless constant separation factor for equilibrium parameter, $R_{\mathrm{L}}$, defined as

$R_{\mathrm{L}}=\frac{1}{1+b C_{0}}$

where $C_{0}$ is the maximum initial concentration of DBP $(\mathrm{mg} / \mathrm{L})$. The value of $R_{\mathrm{L}}$ indicates the type of isotherm to be irreversible $\left(R_{\mathrm{L}}=0\right)$, favorable $\left(0<R_{\mathrm{L}}<1\right)$, linear $\left(\mathrm{R}_{\mathrm{L}}=1\right)$ or unfavorable $\left(R_{\mathrm{L}}>1\right)$ (Dubey and Shiwani 2012). The $R_{\mathrm{L}}$ value in the study was found as 0.014 indicating that this sorption process is favorable.

The value of maximum sorption capacity $\left(q_{\mathrm{m}}\right)$ is of importance to identify which sorbent shows the highest sorption capacity and is useful in scale-up considerations (Deniz and Karaman 2011).Table 2 presents a comparison of the sorption capacity of PLAC with that reported for other sorbents. It can be seen from the table that the PLAC shows a comparable sorption capacity with respect to other sorbents, revealing that the PLAC is suitable for the removal of DBP from aqueous solutions since it has a relatively high sorption capacity.

The Freundlich model suggests a multilayer sorption. Sorption energy exponentially decreases on completion of the sorption centers of a sorbet (Deniz and Karaman 2011). The Freundlich equation is expressed as follows: $\ln q_{\mathrm{e}}=\ln k_{\mathrm{f}}+\frac{1}{n} \ln C_{\mathrm{e}}$

where $k_{\mathrm{f}}$ and $1 / n$ are Freundlich constants, $C_{\mathrm{e}}$ is the equilibrium concentration of the solution $(\mathrm{mg} / \mathrm{L}), q_{\mathrm{e}}$ is the equilibrium adsorption capacity per unit weight adsorbent $(\mathrm{mg} / \mathrm{g})$.

The equilibrium experimental data were fitted using Freundlich isotherm, and the plot of nonlinear form of Freundlich isotherm curves was presented in Fig. $6 \mathrm{~b}$. The Freundlich parameters $k_{\mathrm{f}}, 1 / n$ and $R^{2}$ evaluated from the nonlinear plot using nonlinear regressive analysis were 117.2, 0.4005 and 0.9979. The Freundlich parameter $1 / \mathrm{n}$ relates to the surface heterogeneity. When $0<1 / n<1$, the adsorption is favorable; $1 / n=1$, the adsorption is homogeneous and there is no interaction among the adsorbed species; $1 / n>1$, the adsorption is unfavorable (Deniz and Karaman 2011). In general, $1 / n=0.4005$ indicated that the adsorption behavior of DBP on PLAC was carried out favorable and heterogeneous sorption.

The Dubinin-Radushkevich (D-R) isotherm is more general because it does not assume a homogenous surface or constant sorption potential and was applied to estimate the porosity apparent free energy and the characteristics of sorption (Cerino-Cordova et al. 2013). The following equation indicates the $\mathrm{D}-\mathrm{R}$ isotherm:

$\ln q_{\mathrm{e}}=\ln q_{\mathrm{m}}-B \varepsilon^{2}$

$\varepsilon=R T \ln \left(1+\frac{1}{C_{\mathrm{e}}}\right)$

where $q_{\mathrm{m}}$ is the theoretical saturation capacity $(\mathrm{mg} / \mathrm{g})$, B is a constant related to the sorption energy $\left(\mathrm{mol}^{2} / \mathrm{kJ}^{2}\right), \varepsilon$ is the Polanyi potential, $R$ is the universal gas constant 
Table 2 Comparison of PLAC with other sorbents for DBP equilibrium sorption capacities

\begin{tabular}{llll}
\hline Sorbent & $q_{\mathrm{m}}(\mathrm{mg} / \mathrm{L})$ & Temperature (K) & References \\
\hline Nutshell activated carbon & 104.7 & 328 & Fang and Huang (2009) \\
Marine sediments & 79 & 298 & Xu and Li (2008) \\
Molecularly imprinted polymer (MIP) & 8.713 & room temperature & Shaikh et al. (2012) \\
Nonimprinted polymer (NIP) & 7.199 & room temperature & Shaikh et al. (2012) \\
Ionic liquid (RTIL) modified XAD-4 resin & 4.75 & 308 & Qureshi et al. (2012) \\
$\begin{array}{ll}\alpha \text {-cyclodextrin-linked chitosan bead } \\
\text { Activated sludge }\end{array}$ & $<3.21$ & 298 & Chen et al. (2007) \\
Activated sludge extracellular polymeric substance & 17.6 & room temperature & Fang and Zheng (2004) \\
Polymerization of dimethyl diallyl ammonium chloride & 10.6 & room temperature & Fang and Zheng (2004) \\
$\quad$ and acrylamide (PDA) & 62.5 & room temperature & Zhang and Ren (2013) \\
PLAC & & & 298
\end{tabular}

$[8.314 \mathrm{~J} /(\mathrm{mol} \mathrm{K})]$ and $T$ is the absolute temperature $(\mathrm{K})$. The values of $q_{\mathrm{m}}$ and B were obtained by plotting $\ln q_{\mathrm{e}}$ versus $\varepsilon^{2}$ as seen in Fig. $6 \mathrm{c}$. Through calculated, $q_{\mathrm{m}}$ and B were $124.31 \mathrm{mg} / \mathrm{g}$ and $0.000000029 \mathrm{~mol}^{2} / \mathrm{J}^{2}$, respectively. $R^{2}$ was 0.9115 . The saturation adsorption capacity $q_{\mathrm{m}}$ obtained using D-R isotherm model for adsorption of DBP onto PLAC is $124.31 \mathrm{mg} / \mathrm{g}$, which is close to that obtained from Langmuir isotherm model $(133.33 \mathrm{mg} / \mathrm{g})$.

The mean free energy of adsorption $(E)$, defined as the free energy change when $1 \mathrm{~mol}$ of ion is transferred from infinity in solution to the surface of the sorbent, was calculated from the $\mathrm{B}$ value using the following relation (Cerino-Cordova et al. 2013):

$E=\frac{1}{\sqrt{2 B}}$

The magnitude of $E$ is useful for estimating the type of adsorption process. According to the literature, the value $E(4.149 \mathrm{~kJ} / \mathrm{mol})$ indicated a physiosorption process of adsorption DBP using PLAC (Cerino-Cordova et al. 2013).

Temkin isotherm takes into account sorbate-sorbent interactions and assumes that fall in the heat of sorption is linear rather than logarithmic, as implied in Freundlich equation (Mehrizad et al. 2012). The Temkin relationship in linear form is given as

$q_{\mathrm{e}}=\frac{R T}{b_{\mathrm{T}}} \ln A_{\mathrm{T}}-\frac{R T}{b_{\mathrm{T}}} \ln C_{\mathrm{e}}$

where $A_{\mathrm{T}}(\mathrm{L} / \mathrm{g})$ and $b_{\mathrm{T}}(\mathrm{J} / \mathrm{mol})$ are the Temkin constants. $A_{\mathrm{T}}$ and $b_{\mathrm{T}}$ constants were determined from the slope and intercepts of the plots obtained by plotting $q_{\mathrm{e}}$ versus $\ln C_{\mathrm{e}}$ (Fig. 6d). Through calculated, $A_{\mathrm{T}}$ and $b_{\mathrm{T}}$ were $32.29 \mathrm{~L} / \mathrm{g}$ and $74.43 \mathrm{~J} / \mathrm{mol}$, respectively. $R^{2}$ was 0.9711 .

Therefore, among the above four isotherm models, the Freundlich isotherm model was the best model describing sorption behavior with the highest linear regression correlation coefficient $\mathrm{R}^{2}$, favorable and heterogeneous sorption.

\section{Kinetic studies}

The pseudo-first-order rate model of Lagergren (Kumar et al. 2012) is based on solid capacity and generally expressed as follows:

$\frac{\mathrm{d} q}{\mathrm{~d} t}=k_{1}\left(q_{\mathrm{e}}-q\right)$

where $q_{\mathrm{e}}$ is the amount of solute adsorbed at equilibrium per unit weight of adsorbent $(\mathrm{mg} / \mathrm{g}), q$ is the amount of solute adsorbed at any time $(\mathrm{mg} / \mathrm{g})$ and $k_{1}$ is the pseudofirst-order rate constant $\left(\mathrm{min}^{-1}\right)$. Eq. (10) is integrated for the boundary conditions $t=0$ to $t>0(q=0$ to $q>0)$ and then rearranged to obtain the following linear time dependent function:

$\ln \left(q_{\mathrm{e}}-q\right)=\ln q_{\mathrm{e}}-k_{1} t$

This is the most popular form of pseudo-first-order kinetic model. Fig. 7a showed an example for these plots. Constant $k_{1}$ and correlation coefficient $\left(R^{2}\right)$ had been calculated and summarized 0.0172 and 0.9698 .

The kinetic data were further analyzed using the pseudosecond-order model (Kumar et al. 2012) which, can be expressed as

$\frac{\mathrm{d} q}{\mathrm{~d} t}=k_{2}\left(q_{e}-q\right)^{2}$

Integrating Eq. (12) for the boundary conditions $t=0$ to $t>0$ and $q=0$ to $q>0$ and rearranging to obtain the linearized form which is shown as follows:

$\frac{t}{q}=\frac{1}{k_{2} q_{\mathrm{e}}^{2}}+\frac{t}{q_{\mathrm{e}}}$

where $\mathrm{k}_{2}$ is the pseudo-second-order rate constant [g/ (mg min)]. The plot of $t / q$ versus $t$ of Eq. (13) should give a linear relationship, from which $q_{\mathrm{e}}$ and $k_{2}$ can be determined 
a pseudo-first-order

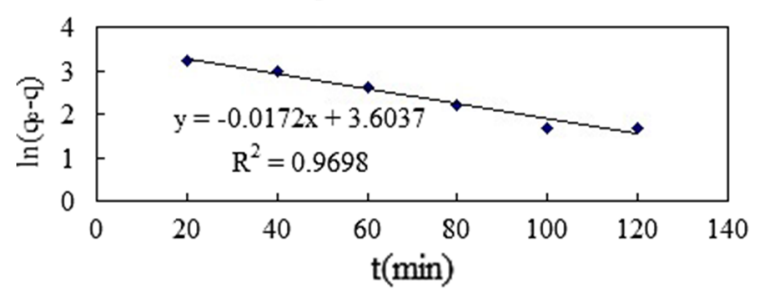

d Elovich

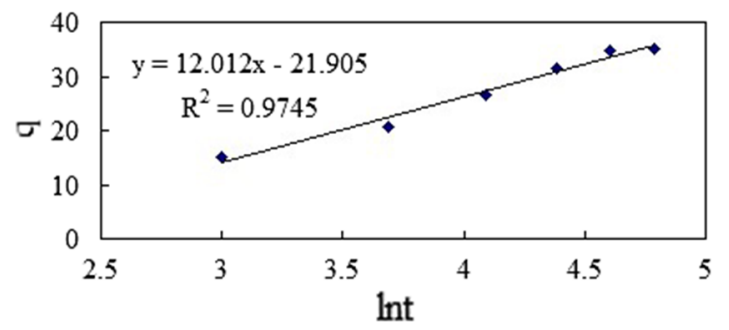

b pseudo-second-order

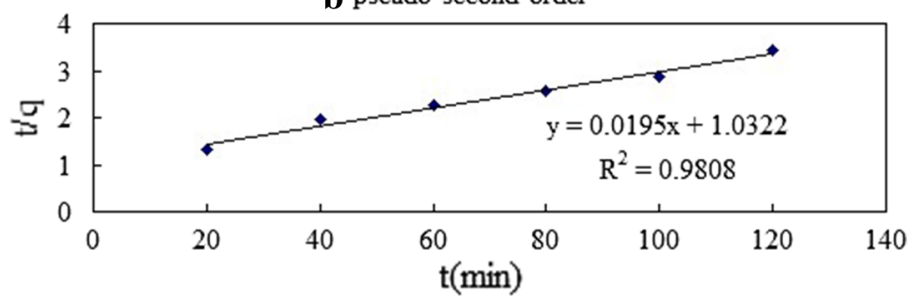

c intraparticle diffusion

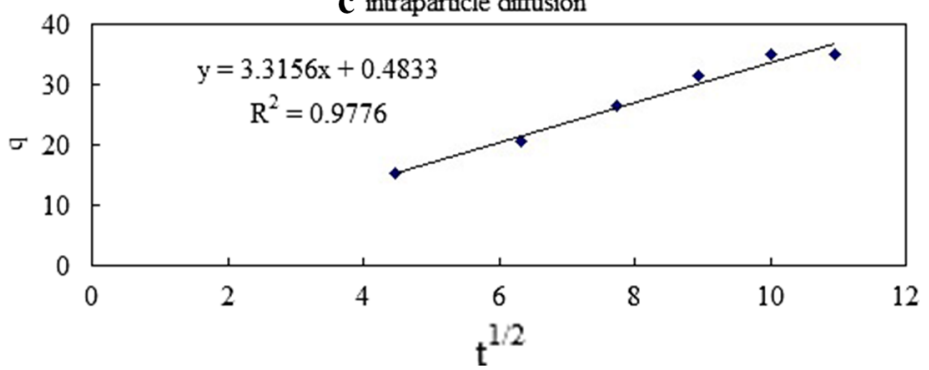

Fig. 7 The linear plots of a Pseudo-first-order kinetic, b Pseudo-second-order kinetic, $\mathbf{c}$ intraparticle diffusion and $\mathbf{d}$ Elovich model

from the slope and intercept of the plot (Fig. 7b). $k_{2}$ and $R^{2}$ had been calculated and summarized 0.000368 and 0.9808 .

The intraparticle diffusion model is used to explain diffusion mechanism of adsorption process. The equation can be described as (Deniz and Karaman 2011):

$q=k_{t} \cdot t^{\frac{1}{2}}+C$

where $k_{\mathrm{t}}$ is the intraparticle diffusion rate constant $[\mathrm{mg} /$ $\left(\mathrm{g} \mathrm{min}^{1 / 2}\right]$ and $\mathrm{C}$ is the intercept. The value of $\mathrm{C}$ relates to the thickness of the boundary layer. The larger $\mathrm{C}$ implies the greater effect of the boundary layer. According to Eq. (14), if adsorption mechanism follows the intraparticle diffusion model, the plot of $q$ against $t^{1 / 2}$ should show linear relationship (Fig. 7c). Slope $k_{t}$ and intercept $C$ were 3.3156 and 0.4833 obtained by linear fitting analysis. Correlation coefficient $R^{2}$ was 0.9776 .

The Elovich model (Deniz and Karaman 2011) is generally expressed as

$q=\frac{1}{\beta} \ln (\alpha \beta)+\frac{1}{\beta} \ln t$

where $\alpha$ is the initial sorption rate $[\mathrm{mg} /(\mathrm{g} \mathrm{min})]$ and $\beta$ is the desorption constant $(\mathrm{g} / \mathrm{mg})$. A plot of $\mathrm{q}$ versus $\ln \mathrm{t}$ should yield a linear relationship with a slope of $(1 / \beta)$ and an intercept of $1 / \beta \ln (\alpha \beta)$ (Fig. 7d). Through calculated, $\alpha$ and $\beta$ were 1.922 and 0.0833 , respectively. Correlation coefficient $R^{2}$ was 0.9745 .

The pseudo-second-order kinetic model $R^{2}$ value for this model is higher than that of the pseudo-first-order kinetic, intraparticle diffusion and Elovich model. Hence, it can be assumed that the adsorption of DBP perfectly follows the pseudo-second-order kinetic model.
Thermodynamic studies

The temperature dependence of the equilibrium constant, $K$, can be used to determine the thermodynamic parameters (Kumar et al. 2008). The Van't Hoff equation is used to evaluate the variation of equilibrium constant with temperature. The integrated form of this equation is given as

$\ln K=\frac{\Delta S^{0}}{R}-\frac{\Delta H^{0}}{R T}$

$K=\frac{q_{\mathrm{e}} \rho}{C_{\mathrm{e}}}$

where $\rho=1,000 \mathrm{~kg} / \mathrm{m}^{3}$, the density of the solution mixture, $\Delta H^{0}$ the standard enthalpy change $(\mathrm{J} / \mathrm{mol}), \Delta S^{0}$ the standard entropy change $[\mathrm{J} /(\mathrm{mol} \mathrm{K}], T$ the absolute temperature $(\mathrm{K})$, and $K$ is the distribution coefficient. The $\Delta H^{0}$ and $\Delta S^{0}$ changes in the process can be determined from the slope and intercept of line obtained by plotting $\ln K$ versus $1 / T$. The Van't Hoff plot for DBP adsorption on PLAC was shown in Fig. 8. The $\Delta H^{0}$ and $\Delta S^{0}$ for DBP can be calculated from the slope of the straight line.

The Gibbs free energy change of adsorption $\left(\Delta G^{0}\right)$ for each temperature is then obtained as (Ozer et al. 2012)

$\Delta G^{0}=\Delta H^{0}-T \Delta S^{0}$

From Eq. (18), $\Delta G^{0}$ was calculated as $-7.31,-7.80$ and $-8.29 \mathrm{~kJ} / \mathrm{mol}$ for the adsorption of DBP on PLAC at 298 , 303 and $308 \mathrm{~K}$, respectively. The negative values of $\Delta G^{0}$ indicate that the sorption process was spontaneous without any induction period. The $\Delta H^{0}$ and $\Delta S^{0}$ changes were determined as $21.92 \mathrm{~kJ} / \mathrm{mol}$ and $98.1 \mathrm{~J} /(\mathrm{mol} \mathrm{K})$, respectively. The positive value of $\Delta S^{0}$ corresponds to an 


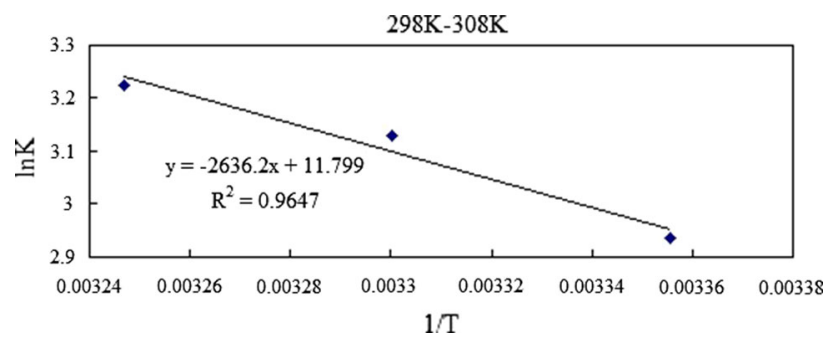

Fig. 8 The effect of temperature on the equilibrium distribution coefficient

increase in the degree of freedom of the sorbed species, suggesting weak interaction between DBP and PLAC which was thermodynamically favorable. The positive value of $\Delta \mathrm{H}^{0}$ showed that the sorption was endothermic process (Deniz and Karaman 2011). Positive value of $\Delta H^{0}$ and $\Delta S^{0}$ also suggested some structural changes in adsorbate and adsorbent (Ahmad et al. 2009).

\section{Conclusion}

The present study shows that PLAC by chemical activation with phosphate can be used as an adsorbent for the removal of DBP from aqueous solutions. The PLAC has a heterogeneous distribution of grain and a well-developed porous structure with different small-size pore. The main elements of PLAC are $24.26 \%$ carbon, $70.65 \%$ oxygen and $3.75 \%$ phosphor. The BET surface area of the sample is $593.52 \mathrm{~m}^{2} / \mathrm{g}$ with the average pore diameter of $6.31 \mathrm{~nm}$. The single-point total pore volume was found to be $0.52 \mathrm{~cm}^{3} / \mathrm{g}$. The infrared spectrum showed the complexity of the material. The maximum DBP adsorption rate was $97.36 \%$, and the maximum adsorption capacity was $48.68 \mathrm{mg} / \mathrm{g}$ at $\mathrm{pH} 13$. The monolayer sorption capacity of the biosorbent for DBP was found as $133.33 \mathrm{mg} / \mathrm{g}$ with the Langmuir isotherm. The equilibrium data fitted with Freundlich isotherm better than Langmuir, D-R and Temkin isotherm. The kinetic data were best described by the pseudo-second-order model better than pseudo-first-order kinetic, intraparticle diffusion and Elovich model. The thermodynamic studies indicated that the sorption process spontaneous, thermodynamically favorable and endothermic. It can be concluded that PLAC can be an alternative material for more costly adsorbents used for DBP removal in wastewater treatment processes.

Acknowledgments The authors express their sincere gratitude to the Natural Science Foundation of the Jiangsu Higher Education Institutions of China (12KJB560004), Housing and Urban and Rural Construction Technology Program of Ministry of Science and Project (2011-K7-2), the project of Jiangsu government scholarship for study abroad (2012196) and A Project Funded by the Priority Academic
Program Development of Jiangsu Higher Education Institutions (PAPD) for financial support.

\section{References}

Ahmad A, Rafatullah M, Sulaiman O, Ibrahim MH, Hashim R (2009) Scavenging behaviour of meranti sawdust in the removal of methylene blue from aqueous solution. J Hazard Mater 170(1):357-365

Behera SK, Oh SY, Park HS (2012) Sorptive removal of ibuprofen from water using selected soil minerals and activated carbon. Int J Environ Sci Technol 9(1):85-94

Carvalho AP, Cardoso B, Pires J, de Carvalho MB (2003) Preparation of activated carbons from cork waste by chemical activation with KOH. Carbon 41(14):2873-2876

Cerino-Cordova FJ, Diaz-Flores PE, Garcia-Reyes RB, Soto-Regalado E, Gomez-Gonzalez R, Garza-Gonzalez MT, BustamanteAlcantara $\mathrm{E}$ (2013) Biosorption of $\mathrm{Cu}(\mathrm{II})$ and $\mathrm{Pb}$ (II) from aqueous solutions by chemically modified spent coffee grains. Int J Environ Sci Technol 10(3):611-622

Chang BV, Lu YS, Yuan SY, Tsao TM, Wang MK (2009) Biodegradation of phthalate esters in compost-amended soil. Chemosphere 74(6):873-877

Chen CY, Chen CC, Chung YC (2007) Removal of phthalate esters by alpha-cyclodextrin-linked chitosan bead. Bioresour Technol 98(13):2578-2583

Chi JE, Yang Q (2012) Effects of Potamogeton crispus L. on the fate of phthalic acid esters in an aquatic microcosm. Water Res 46(8):2570-2578

Crini G (2005) Recent developments in polysaccharide-based materials used as adsorbents in wastewater treatment. Prog Polym Sci 30(1):38-70

Deniz F, Karaman S (2011) Removal of Basic Red 46 dye from aqueous solution by pine tree leaves. Chem Eng J 170(1):67-74

Dubey A, Shiwani S (2012) Adsorption of lead using a new green material obtained from Portulaca plant. Int $\mathbf{J}$ Environ Sci Technol 9(1):15-20

Fang ZQ, Huang HJ (2009) Adsorption of di-n-butyl phthalate onto nutshell-based activated carbon. Equilibrium, kinetics and thermodynamics. Adsorpt Sci Technol 27(7):685-700

Fang HHP, Zheng HH (2004) Adsorption of phthalates by activated sludge and its biopolymers. Environ Technol 25(7):757-761

Fang CR, Long YY, Shen DS (2009) Comparison on the removal of phthalic acid diesters in a bioreactor landfill and a conventional landfill. Bioresour Technol 100(23):5664-5670

Fang CR, Yao J, Zheng YG, Jiang CJ, Hu LF, Wu YY, Shen DS (2010) Dibutyl phthalate degradation by Enterobacter sp T5 isolated from municipal solid waste in landfill bioreactor. Int Biodeter Biodegr 64(6):442-446

Han XL, Wang W, Ma XJ (2011) Adsorption characteristics of methylene blue onto low cost biomass material lotus leaf. Chem Eng J 171(1):1-8

Health Ministry of People's Republic of China (2007) Standards for drinking water quality of China (GB5749-2006)

Jibril B, Houache O, Al-Maamari R, Al-Rashidi B (2008) Effects of $\mathrm{H}_{3} \mathrm{PO}_{4}$ and $\mathrm{KOH}$ in carbonization of lignocellulosic material. J Anal Appl Pyrolysis 83(2):151-156

Julinova M, Slavik R (2012) Removal of phthalates from aqueous solution by different adsorbents: a short review. J Environ Manage 94(1):13-24

Kumar A, Prasad B, Mishra IM (2008) Adsorptive removal of acrylonitrile by commercial grade activated carbon: kinetics, equilibrium and thermodynamics. J Hazard Mater 152(2):589-600 
Kumar R, Jain SK, Misra RK, Kachchwaha M, Khatri PK (2012) Aqueous heavy metals removal by adsorption on beta-diketonefunctionalized styrene-divinylbenzene copolymeric resin. Int J Environ Sci Technol 9(1):79-84

Lang W, Buranaboripan W, Wongchawalit J, Parakulsuksatid P, Vanichsriratana W, Sakairi N, Pathom-aree W, Sirisansaneeyakul S (2013) Biosorption of lead from acid solution using chitosan as a supporting material for spore forming-fungal biomass encapsulation. Int J Environ Sci Technol 10(3):579-590

Li LS, Zhu WP, Chen L, Zhang PY, Chen ZY (2005) Photocatalytic ozonation of dibutyl phthalate over $\mathrm{TiO}_{2}$ film. J Photoch Photobio A 175(2-3):172-177

Li HY, Qu JH, Liu HJ (2006) Removal of a type of endocrine disruptors-di-n-butyl phthalate from water by ozonation. J Environ Sci 18(5):845-851

Mehrizad A, Zare K, Aghaie H, Dastmalchi S (2012) Removal of 4-chloro-2-nitrophenol occurring in drug and pesticide waste by adsorption onto nano-titanium dioxide. Int J Environ Sci Technol 9(2):355-360

Mendez-Diaz JD, Daiem MMA, Rivera-Utrilla J, Sanchez-Polo M, Bautista-Toledo I (2012) Adsorption/bioadsorption of phthalic acid, an organic micropollutant present in landfill leachates, on activated carbons. J Colloid Interface Sci 369:358-365

Ooka C, Yoshida H, Suzuki K, Hattori T (2004) Highly hydrophobic $\mathrm{TiO}_{2}$ pillared clay for photocatalytic degradation of organic compounds in water. Micropor Mesopor Mat 67(2-3):143-150

Ozer ET, Osman B, Kara A, Besirli N, Gucer S, Sozeri H (2012) Removal of diethyl phthalate from aqueous phase using magnetic poly(EGDMA-VP) beads. J Hazard Mater 229:20-28
Qureshi UA, Solangi AR, Memon SQ, Taqvi SIH, Memon N (2012) Ionic liquid modified resin for the adsorptive removal of dibutyl phthalate: equilibrium, kinetic, and thermodynamic studies. Clean-Soil Air Water 40(6):630-639

Ranganathan K (2000) Chromium removal by activated carbons prepared from Casurina equisetifolia leaves. Bioresour Technol 73(2):99-103

Ren YM, Dong Q, Feng J, Ma J, Wen Q, Zhang ML (2012) Magnetic porous ferrospinel $\mathrm{NiFe}_{2} \mathrm{O}_{4}$ : a novel ozonation catalyst with strong catalytic property for degradation of di-n-butyl phthalate and convenient separation from water. J Colloid Interface Sci 382:90-96

Salim CJ, Liu H, Kennedy JF (2010) Comparative study of the adsorption on chitosan beads of phthalate esters and their degradation products. Carbohyd Polym 81(3):640-644

Shaikh H, Memon N, Khan H, Bhanger MI, Nizamani SM (2012) Preparation and characterization of molecularly imprinted polymer for di (2-ethylhexyl) phthalate: application to sample cleanup prior to gas chromatographic determination. J Chromatogr A 1247:125-133

Xu XR, Li XY (2008) Adsorption behaviour of dibutyl phthalate on marine sediments. Mar Pollut Bull 57(6-12):403-408

Zhang P, Ren BZ (2013) Inverse emulsion polymerization of dimethyl diallyl ammonium chloride and acrylamide for water treatment. Asian J Chem 25(7):3966-3970 